\title{
Erratum to: Is endoscopic closure with clips effective for both diagnostic and therapeutic colonoscopy-associated bowel perforation?
}

Dong-Hoon Yang · Jeong-Sik Byeon · Kyung-Hoon Lee • Soon Man Yoon • Kyung Jo Kim • Byong Duk Ye • Seung-Jae Myung • Suk-Kyun Yang • Jin-Ho Kim

Published online: 17 April 2010

(C) Springer Science+Business Media, LLC 2010

Erratum to: Surg Endosc

DOI 10.1007/s00464-009-0746-2

On page 4 , line 9 , the phrase “... procedures and 25 $(0.22 \%)$ during or after..." should be changed to “... procedures and $25(0.209 \%)$ during or after...".

The online version of the original article can be found under doi:10.1007/s00464-009-0746-2.

D.-H. Yang · J.-S. Byeon $(\bowtie) \cdot$ K.-H. Lee .

S. M. Yoon - K. J. Kim · B. D. Ye - S.-J. Myung .

S.-K. Yang $\cdot$ J.-H. Kim Department of Internal Medicine, University of Ulsan College

of Medicine, Asan Medical Center, 388-1, Pungnap-2dong,

Songpa-gu, Seoul 138-736, Korea

e-mail: jsbyeon@amc.seoul.kr 